\title{
Correlation-regression models for calculating the weight of small-scale aircraft gas turbine engines
}

\author{
Evgeny Filinov, Daria Kolmakova, Sergey Avdeev and Sergey Krasilnikov \\ Samara National Research University, Department of Aircraft Engine Theory, Samara, Russian Federation
}

\begin{abstract}
Several new correlation-regression models of weight calculation for small-scale aircraft gas turbine engines are proposed for their conceptual design stage. A comparison of the obtained weight models with each other and with the Kuz'michev model is carried out. Based on the obtained results, conclusions about the feasibility and scope of their application are drawn. New correlation-regression models differ from each other in the number of input parameters, as well as in the accuracy of forecasting the weight. In the course of the work, a database of main data and thermodynamic parameters of turbofan engines (TFE) is created consisting of 92 small-scale TFEs with thrust less than $50 \mathrm{kN}$. Based on the collected statistics, formulas were obtained that allow calculating the weight at the initial stage of engine design. The error in calculating the weight by these models is in range from $10 \%$ to $30 \%$.
\end{abstract}

\section{Introduction}

In general, weight estimation of gas turbine engine (GTE) is required at the initial design stages to calculate its technical and economic efficiency and to optimize its parameters. The future of the project depends to a large extent on the results of the conceptual design. At later stages of the design, it is possible to use component models for calculating weight, and it is also possible to estimate the weight based on layout drawings, which, however, cannot be done at the conceptual design stage due to insufficient information on the project. In this regard, correlation-regression models of weight are used at the initial stages of the design that are based on the statistical data of manufactured gas turbine engines. The accuracy of such models depends on the number of the engines involved in the statistics, the number of parameters used for calculation and the size of the engine.

At present, small-scale gas-turbine engines are widely used. These engines are used for light aircraft, unmanned aerial vehicles, cruise missiles, as auxiliary power units, and in the long term they are considered as a part of distributed power units. The prospect of this trend requires careful research, in particular the creation of as much as possible more accurate mathematical models of weight, as well as the refinement of existing ones. A large influence on the accuracy of the weight calculation has the dimension of the gas turbine engine: an increase in the calculation error is observed for small-scale engines. This is due primarily to the fact that the small-scale GTE has a larger proportion of aggregates and this is difficult to consider parametrically, and due to the lack of statistics for small-scale turbojet engines. The relevance of the work is due to the need to develop methods for the optimal design of small-scale gas turbine engines.

The purpose of this work is to develop new models of weight calculation for the initial stages of designing small-scale gas turbine engines, as well as in assessing the accuracy of the models obtained and determining the possibility of their further application.

\section{Weight models}

The development of new models is carried out in several stages. At the first stage, the initial data were searched and prepared. The accuracy of the models being developed largely depends on the reliability of the information about the engine parameters collected at this stage.

The second stage of developing the model included 4 steps:

1. Selection of model input parameters;

2. Definition of the general form of the model;

3. Calculation of the statistical coefficients of the model;

4. Determination of statistical estimates of the model.

At the final stage, the results are analyzed and corresponding conclusions on the applicability of the model are drawn.

\subsection{Search for initial data and their preparation}

To create a new model for the weight calculation, a database is compiled that include the main parameters of 92 gas turbine engines with thrust less than $50 \mathrm{kN}$. It is 
impossible to find a part of the parameters for the weight calculation in open publications, so different models use a different number of engines to calculate the weight, depending on the number of input parameters. Statistics are made up of various types of turbojet and turbofan engines for both military and civil aviation.

The search for the initial data is carried out based on the analysis of [1-12].

Table 1. The range for variation of workflow parameters in the engine sampling.

\begin{tabular}{|c|c|c|}
\hline Parameter & min & max \\
\hline $\begin{array}{c}\mathrm{G}_{\text {a.t-o }}, \mathrm{kg} / \mathrm{s} \\
\text { (takeoff) }\end{array}$ & 5.3 & 153 \\
\hline $\mathrm{P}_{\mathrm{t}-\mathrm{o}}, \mathrm{kN}$ (takeoff) & 2.12 & 50 \\
\hline$\pi_{\mathrm{C}}$ & 3.8 & 30 \\
\hline $\mathrm{T}^{*}, \mathrm{~K}$ & 1039 & 1850 \\
\hline $\mathrm{m}$ & 0 & 9 \\
\hline $\mathrm{W}_{\text {eng, }} \mathrm{kg}$ & 41 & 1126 \\
\hline $\mathrm{D}_{\text {in }}, \mathrm{mm}$ & 0.305 & 1.272 \\
\hline$\pi_{\mathrm{c} . \text { fan }}$ & 1.29 & 3.9 \\
\hline Production year & 1950 & 2014 \\
\hline
\end{tabular}

It can be seen from Table 1 that the range of variation of the workflow parameters for the 92 engines is quite wide. The results of the analysis of the weight models will be valid for most modern small-scale turbofan engines, since their parameters fit into this range. Regularization was carried out using the developed at the Samara National Research University software "ASTRA" [13-15] as task of minimization of discrepancies between the published and calculated values (e.g. SFC, thrust, air mass flow rate, etc.), while the efficiency ratios, losses coefficients and other parameters with unknown values were optimizable variables.

\subsection{Creating a weight model}

Based on the collected statistical data, 4 new models were proposed for calculating the weight of small-scale TFE. They differ from each other in the accuracy of the calculation, the number of parameters and the complexity. Later on, the obtained models are compared and conclusions on the field of their application are made.

\subsubsection{Weight model No. 1}

The first weight model is obtained by approximating the statistical data on the engine weight, depending on the total air mass flow rate through the engine. A power function is chosen that most accurately describes the statistical data.

The expression for calculating the weight of a gas turbine engine according to model No. 1 has the following form:

$$
\mathrm{W}_{\mathrm{eng}}=14.7 \cdot \mathrm{G}_{\mathrm{a} \Sigma}^{0.818}
$$

This model involves statistics on 88 TFEs. The rootmean-square deviation is $25.5 \%$.

\subsubsection{Weight model No. 2}

The second model is also an approximation, but in this case by the value of thrust. The formula for calculating the weight of the engine is as follows:

$$
\mathrm{W}_{\mathrm{eng}}=21.55 \cdot \mathrm{P}_{\mathrm{t}-\mathrm{o}}^{0.98}
$$

The coefficients of the approximating function are determined based on the 92 gas turbine engines. The value of the relative root-mean-square deviation for this model is $18.6 \%$.

\subsubsection{Weight model No. 3}

The third model is a product of power functions of the main engine parameters: engine thrust, the total pressure ratio and bypass ratio. The exponents are determined based on the collected statistics. The formula for calculating the weight for this model is as follows:

$$
\mathrm{W}_{\text {eng }}=19.27 \cdot \mathrm{P}_{\mathrm{t}-\mathrm{o}}^{0.92} \cdot \pi_{\mathrm{c} \Sigma}^{0.11} \cdot \mathrm{m}^{0.03}
$$

This model involves 77 TFEs. The value of the relative root-mean-square deviation of this model is $13.4 \%$.

\subsubsection{Weight model No. 4}

The fourth model uses the total air mass flow rate, the pressure ratio, the gas temperature in front of the turbine, and bypass ratio to calculate the weight. Thus, this model uses the largest number of input parameters among all the proposed models. The formula for calculating the weight of a gas turbine engine according to this model is as follows:

$$
\begin{gathered}
\mathrm{W}_{\mathrm{eng}}=6.88\left(\frac{\mathrm{G}_{\mathrm{a} \Sigma \mathrm{t}-\mathrm{o}}}{\mathrm{m}+1}\right)^{1.14} \cdot\left(\left(\frac{\mathrm{T}_{4}^{*}}{288}\right)^{0.21}+3.742 \cdot \pi_{\Sigma}^{0.133}\right)+ \\
4.82 \cdot \mathrm{G}_{\mathrm{a} \Sigma \mathrm{t}-\mathrm{o}}^{0.834} \cdot \mathrm{m}^{0.223}
\end{gathered}
$$

$\mathrm{G}_{\mathrm{a} \Sigma \mathrm{t}-\mathrm{o}}-$ total air mass flow rate through the engine;

$\pi_{\Sigma}$ - the total pressure ratio of the compressor;

$\mathrm{m}$ - bypass ratio;

$\mathrm{T}_{4}^{*}$ - gas temperature in front of turbine.

The formula consists of two terms. The first term describes the weight of the core engine, and the second describes the weight of bypass duct.

The statistical coefficients are calculated in relation to TFE.

The basis for this model is 57 TFE. The value of the relative mean-quadratic deviation for this model is $10.1 \%$.

\subsubsection{Kuz'michev model}

The Kuz'michev weight model depends on five parameters of the gas turbine engine:

$$
W_{\text {eng }}=f\left(m, \pi_{c \Sigma}, G_{a}, T_{4}^{*}, \pi_{F}\right)
$$

In general, the model has the following form: 


$$
W_{\text {eng }}=\left(W_{I}+W_{I I}+W_{m . c h}+W_{a b}\right) \cdot k_{e} \cdot k_{l f}
$$

where: $W_{\mathrm{I}}=B\left(G_{a \text { I sp.F }}\right)^{k_{1}}\left[\left(\frac{\pi_{\mathrm{C} \Sigma}^{*}}{\pi_{\mathrm{F}}^{*}}\right)^{0,286}-1\right]^{k_{2}} k_{T_{4}^{*}}-$ weight of the engine core;

$$
G_{a \text { I sp.F }}=G_{a \text { I }} \frac{1}{\pi_{\mathrm{F}}} \sqrt{1+\left(\pi_{\mathrm{F}}^{0,286}-1\right) \frac{1}{\eta_{\mathrm{F}}}}-\text { primary air }
$$

mass flow rate at take-off, reduced by the parameters at the fan exit;

$W_{\text {II }}=2,865 \cdot G_{\mathrm{a} \Sigma \mathrm{t}-\mathrm{o}}^{0,903} m^{0,104} \pi_{\mathrm{F}}^{1,193}-$ weight of the fan, fan turbine and bypass ducting;

$W_{\mathrm{m} . \mathrm{ch}}=2,316 \cdot G_{a \Sigma \mathrm{t}-\mathrm{o}}^{0,753}-$ weight of the mixing chamber (if present);

$W_{\mathrm{ab}}=2,9 \cdot G_{a \Sigma \mathrm{t}-\mathrm{o}}-$ weight of the afterburner (if present);

$k_{\mathrm{e}}-$ coefficient of engine sophistication impact (changes over the years) (Fig. 1);

$k_{\mathrm{lf}}$ - coefficient of engine life impact:

$$
k_{\mathrm{lf}}\left\{\begin{array}{l}
1,0 \ldots 1,07-\text { for subsonic airliners; } \\
1,0 \text { - for military long-range aircraft; } \\
0,9 \text { - for fighters. }
\end{array}\right.
$$

$k_{T_{4}^{*}}$ - coefficient of turbine cooling system impact:

$$
k_{T_{4}^{*}}=1+2 \cdot 10^{-4}\left(T_{4 \max }^{*}-1200\right) .
$$

The values of the coefficients $\mathrm{B}, \mathrm{k} 1, \mathrm{k} 2$ are determined based on the collected statistical data on small-scale GTEs. The total number of engines including in the statistics is 52 . The values of the coefficients $\mathrm{B}, \mathrm{k} 1$, $\mathrm{k} 2$ are given in Table 2.

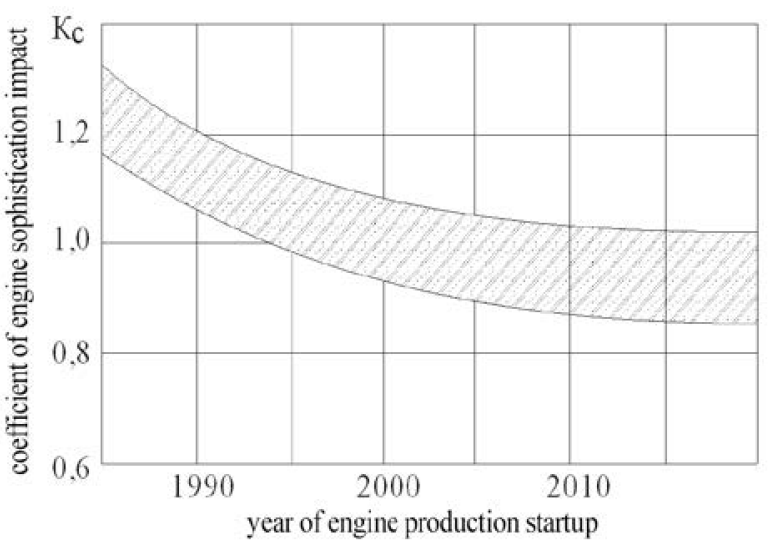

Figure 1. Coefficient of engine sophistication impact against the year of engine production startup.

Table 2. Values of coefficients for engine weight estimation.

\begin{tabular}{|c|c|c|c|c|c|c|}
\hline \multirow{2}{*}{$\begin{array}{c}\text { Type of } \\
\text { GTE }\end{array}$} & \multicolumn{3}{|c|}{$\mathbf{0 . 5}<\mathbf{G}_{\text {I I s. F }}<\mathbf{1 0} \mathbf{~ k g} / \mathbf{s}$} & \multicolumn{3}{|c|}{$\mathbf{1 0}<\mathbf{G}_{\text {a I sp. F }}<\mathbf{2 0} \mathbf{~ k g} / \mathbf{s}$} \\
\cline { 2 - 7 } & $\boldsymbol{B}$ & $\boldsymbol{k}_{\mathbf{1}}$ & $\boldsymbol{k}_{\mathbf{2}}$ & $\boldsymbol{B}$ & $\boldsymbol{k}_{\mathbf{1}}$ & $\boldsymbol{k}_{\mathbf{2}}$ \\
\hline $\begin{array}{l}\text { Turbojet } \\
\text { Turbofan } \\
\boldsymbol{\pi}_{\mathrm{C} \Sigma \mathrm{t}-\mathrm{o}}^{*}>5\end{array}$ & 2.18 & 0.96 & 0.5 & 3.05 & 1 & 0.5 \\
\hline
\end{tabular}

\section{Analysis of the results}

The accuracy of the model is characterized by the magnitude of the relative deviation of the calculated value of the engine weight from its real value. It is believed that statistical models have satisfactory accuracy, if the average error is not more than $10-15 \%$ [5]. For the models proposed in this paper, their accuracy is estimated by four main factors: standard deviation $(\sigma)$, average relative approximation error (A), correlation coefficient $(\mathrm{r})$ and Fisher test $\left.\left(\mathrm{F}_{\text {table }} / \mathrm{F}_{\text {calculated }}\right)\right)$ (Table 3).

The model, which depends on the total air mass flow rate through the fan, has the highest standard deviation. This is due to the fact that the model has only one input parameter and does not take into account, therefore, all factors affecting the weight of the GTE.

The approximation model by the engine thrust has a standard deviation less than model No. 1. The reason for the reduction in the root-mean-square deviation is that the thrust most fully characterizes the working process of the engine, since it has a unique dependence on all engine parameters. In particular, engine thrust takes into account the value of the total air mass flow rate through the engine.

Accuracy of weight calculation is raised for model No. 3, concerning models No. 1 and No. 2, due to increase in quantity of input parameters.

Table 3. Comparison of the accuracy of mathematical models.

\begin{tabular}{|c|c|c|c|c|c|}
\hline Model & No. 1 & No. 2 & No. 3 & No. 4 & $\begin{array}{c}\text { Kuz'michev } \\
\text { model }\end{array}$ \\
\hline$\sigma$ & 25.5 & 18.6 & 13.4 & 10.1 & 13.5 \\
\hline$A$ & 20.2 & 12.8 & 10.0 & 8.7 & 10.4 \\
\hline$r$ & 0.79 & 0.953 & 0.969 & 0.971 & 0.959 \\
\hline$F_{\text {tabl }} /$ & $\begin{array}{c}3.95< \\
\left.\left.F_{\text {calc }}\right)\right)\end{array}$ & $\begin{array}{c}3.95< \\
898\end{array}$ & $\begin{array}{c}2.74< \\
368\end{array}$ & $\begin{array}{c}2.56< \\
215\end{array}$ & $3.2<270$ \\
\hline
\end{tabular}

Model No. 4 uses the largest number of input parameters in comparison with the weight models No. 1, No. 2 and No. 3. Due to this, this model has the least standard deviation.

Kuz'michev model uses more input parameters than all models considered above.

Based on the obtained results, the following conclusions can be drawn:

At the stage of the conceptual GTE design, models No. 4 and Kuz'michev model are most preferable.

Models No. 1, No. 2 and No. 3 should be used for preliminary estimation of the weight of the propulsion engine when designing an aircraft.

The charts of the deviation of the actual value of the weight from the calculated value are plotted (Figures 2-6).

\section{Conclusion}

As a result of the research, a database of parameters for small-scale turbofan engines are created, on the basis of 
which four correlation-regression mathematical models are developed to calculate the weight of engines. For some engines, information about the parameters of the workflow is not incomplete. Often there are no parameters such as the gas temperature in front of the turbine and the total pressure ratio. This circumstance imposes additional restrictions when creating new weight models. The number of input parameters of the model characterizes its complexity and design stage, in which the model allows to calculate the weight. The choice of the working process parameters used in the models is made in such a way as to uniquely determine the nature of the change in the weight of the entire engine.

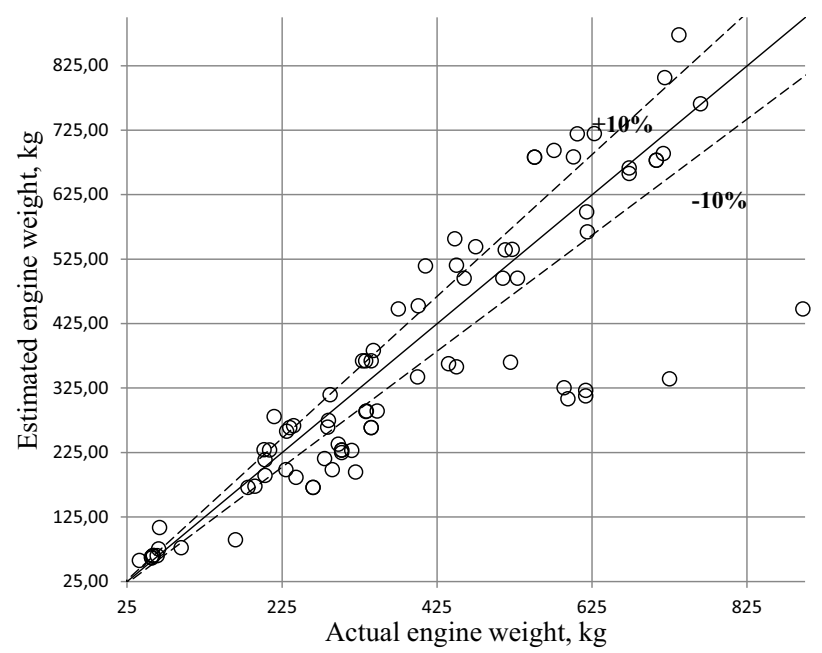

Figure 2. Deviation of the calculated value of the weight from the actual value for model No. 1 .

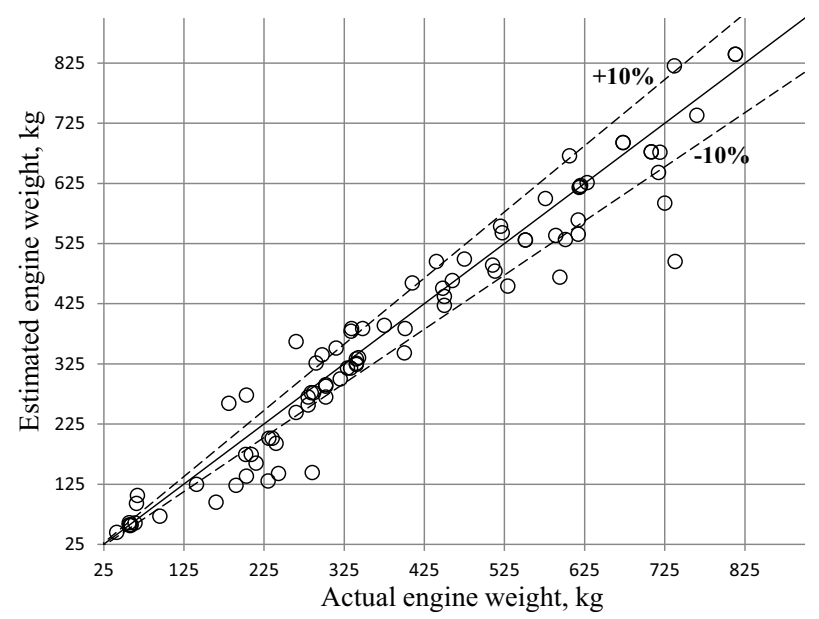

Figure 3. Deviation of the calculated value of the weight from the actual value for model No. 2.

The application of models with one input parameter enabled the use of most of the engines in statistics. For model No. 1, using the total air mass flow rate as an input parameter, the relative mean-square deviation is $25.5 \%$. For model No. 2, with the thrust as input parameter, this value is $18.6 \%$. These models can be used for preliminary estimation of the weight of the engine in the design of an aircraft.

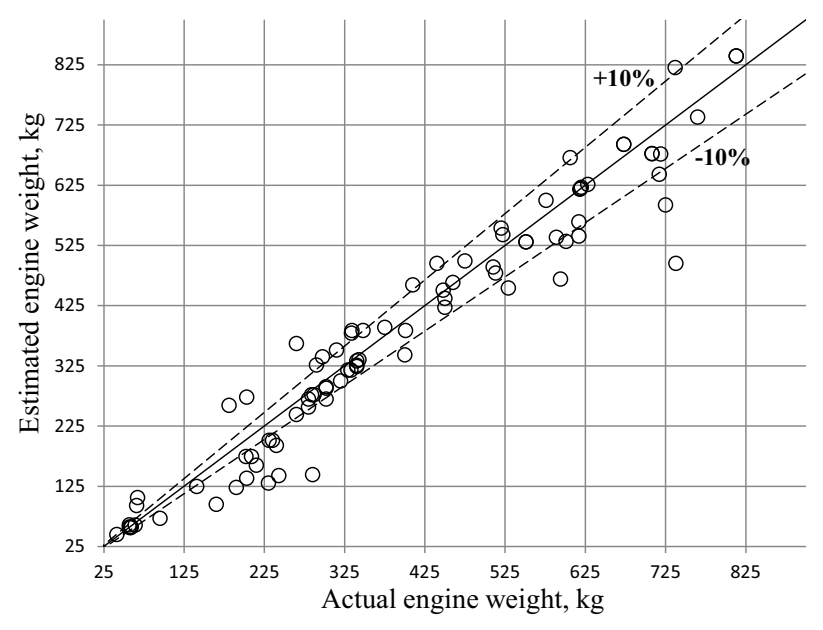

Figure 4. Deviation of the calculated value of the weight from the actual value for model No. 3 .

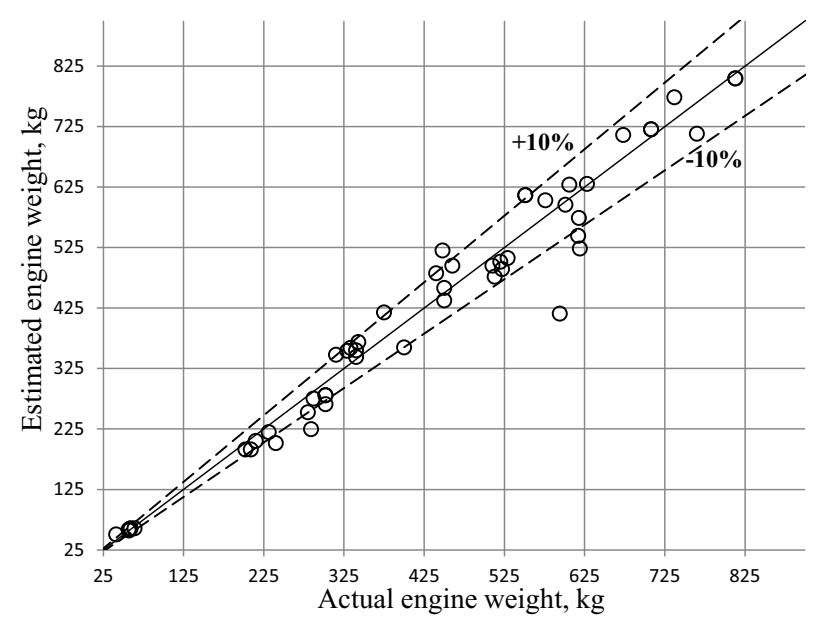

Figure 5. Deviation of the calculated value of the weight from the actual value for model No. 4 .

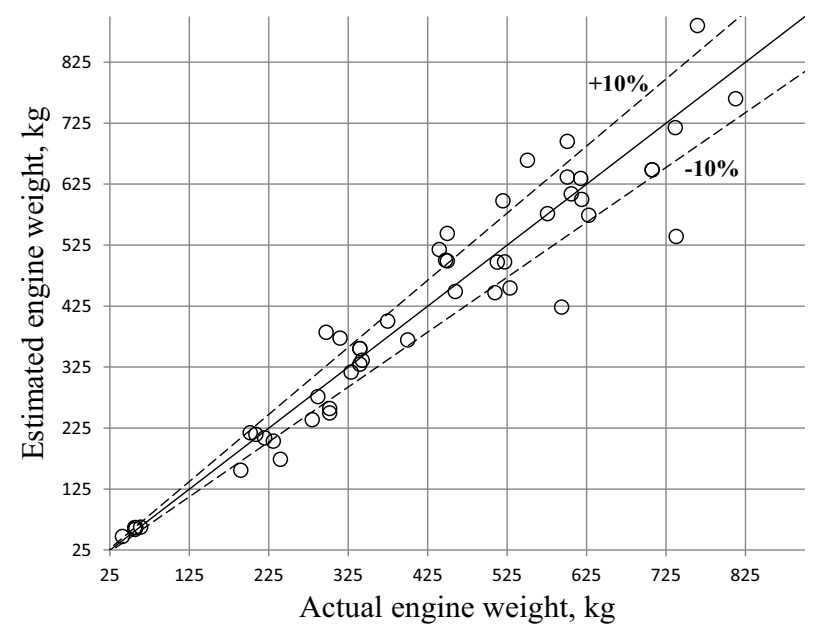

Figure 6. Deviation of the calculated value of the weight from the actual value for Kuz'michev model after the refinement of statistical coefficients.

Models No. 3 and No. 4 have the smallest standard deviation has among all proposed four new weight models. This is due to the fact that they use a greater number of input parameters, taking into account the 
largest number of factors affecting the weight of the gas turbine engine. For model No. 4, the relative standard deviation is $10.1 \%$, and for model No. 3 is $13.4 \%$. Thus, models No. 3 and No. 4 have a satisfactory prediction accuracy (standard deviation is less than 15\%) [5].

At the stage of the conceptual design of the GTE, the most preferred models are No. 4 and Kuz'michev model.

\section{Nomenclature}

$\begin{array}{ll}D & =\text { diameter } \\ G & =\text { mass flow rate } \\ m & =\text { bypass ratio } \\ P & =\text { thrust } \\ T^{*} & =\text { total temperature } \\ W & =\text { weight } \\ \pi & =\text { pressure ratio } \\ \sigma & =\text { standard deviation } \\ a & =\text { air } \\ \mathrm{ab} & =\text { afterburner } \\ \mathrm{C} & =\text { compressor } \\ \text { eng } & =\text { engine } \\ \mathrm{F} & =\text { fan } \\ \mathrm{m} \cdot \mathrm{ch} & =\text { mixing chamber } \\ \mathrm{t}-\mathrm{o} & =\text { take-off } \\ \Sigma & =\text { overall } \\ 4 & =\text { section after combustion chamber } \\ \mathrm{I} & =\text { engine core } \\ \mathrm{II} & =\text { low-pressure spool }\end{array}$

\section{Acknowledgment}

This work was supported by the Ministry of education and science of the Russian Federation in the framework of the implementation of the Program of increasing the competitiveness of Samara University among the world's leading scientific and educational centers for 2013-2020 years.

\section{References}

1. E. Torenbeek, Synthesis of Subsonic Airplane Design (Delft University Press, Rotterdam, 1976)

2. D.P. Raymer, Aircraft Design: A Conceptual Approach (AIAA, Washington, 1992)

3. L.R. Jenkinson, P. Simpkin, D. Rhodes, Civil Jet Aircraft Design (AIAA, Reston, 1999)

4. C. Svoboda, Aircraft Design, 3, 17 (2000)

5. P. Lolis, Development of a Preliminary Weight Estimation Method for Advanced Turbofan Engines (Cranfield University, Cranfield, 2014)

6. A. Guha, D. Boylan, P. Gallagher, Proc. IMechE Part G: J Aerospace Eng., 227, 502 (2012)

7. A.R. Byerley, A.J. Rolling, K.W. Van Treuren, Proceedings of ASME Turbo Expo, 4 (2013)

8. E. Roux, Turbofan and Turbojet Engines: Database Handbook (Elodie Roux, Blagnac, 2007)

9. L.I. Sorkin, G.K. Vedeshkin, A.N. Knyazev, Foreign aviation engines and power plants: reference book (CIAM, Moscow, 2010)

10. V.A. Skibin, V.I. Solonin, Efforts of the leading companies developing the aviation engines in creating the future engines: analytical survey (CIAM , Moscow, 2010)

11. I.G. Shustov, Engines of 1944-2000: aviation, rocket, naval engines and power plants. Encyclopedia (AKS-Konversalt, Moscow, 2000)

12. J.D. Mattingly, W.H. Heiser, D.T. Pratt, Aircraft Engine Design (AIAA, Reston, 2002)

13. V.S. Kuz'michev, Y.A. Ostapyuk, A.Y. Tkachenko, I.N. Krupenich, E.P. Filinov, IJMERR, 6, 28 (2017)

14. I.N. Krupenich, E.P. Filinov, Y.A. Ostapyuk, A.Yu. Tkachenko, IJMERR, 6, 36 (2017)

15. V.S. Kuz'michev, A.Y. Tkachenko, Y.A. Ostapyuk, I.N. Krupenich, E. P. Filinov, ICMSC 2017, 136 (2017) 